\title{
PERCEPTIONS OF HUMAN RESOURCES MANAGERS ON TELECOMMUTING CONCEPT Implementation in Malaysian Firms
}

\author{
Noorliza Karia \\ Yuserrie Zainuddin \\ Muhammad Hasmi Abu Hassan Asaari
}

Telecommuting concept has been a new phenomenon for most of Malaysian firms, especially for human resource managers. Further, the drive towards promoting the telecommuting concept need to be done as part of paradigm change as Malaysia is becoming an industrialized nation -Vision 2020 of the Prime Minister. This study was conducted on the Malaysian human resource managers in representing theirfirm's stand on the telecommuting concept. The purpose of this paper is to explore the level of acceptance of the telecommuting concept by the human resource managers. It was discovered that high percentage of the human resource managers shown their concern on the acceptance of the telecommuting concept.

Keywords: quality of work life; telecommuting; telework; telecommuting 


\section{Introduction}

Malaysia is moving toward an industrialized nation by the year 2020-vision of the Prime Minister. Therefore, various mega projects, such as Multimedia Super Corridor (MSC), new port of West Port, new airport of Sepang, had been implemented. All of the infrastructures are made available in the vision of an industrialized nation and further facing the globalization challenges.

Further in manning the coming industrialized nation, Malaysia needs a pool of skill workers in various expertises. These workers are needed in ensuring the nation's excellence to be at the top notch at all time. Moreover, the scarcity of skill workers throughout the nation needs to be addressed by the Ministry of Human Resource and the relevant agencies regardless public or private organizations. Therefore, the alternative towards resolving the scarcity of skill workers can be reduced by the implementation of telecommuting concept in Malaysia. As they can work from any place, any time.

\section{Problem Statement}

Telecommuting concept is a new concept for Malaysians. As for Malaysia, there has been a minimal study on the telecommuting; therefore studies from Western researchers will be used as basis in establishing the acceptance of the telecommuting concept by firms in Malaysia. Majority of the companies in this country do not officially recognize an individual to work based on telecommuting concept. On the other hand, individuals if given an opportunity, they would like to be on the telecommuting concept as they are more in control over their work and personal life. Therefore, views of human resource managers will be used in determining the firm's acceptance.

\section{Objective}

This study will explore the acceptance level of Malaysian firms toward the telecommuting concept based on the inputs given by human resource managers.

\section{Literature Review}

\section{Telecommuting}

The label "telecommuter" can fit anyone who worked in a home or mobile office for an employer somewhere elsewhether it is daily or weekly, at a few miles' distance or halfway around the world (Johnson 1999). In the other words, a telecommuter was an employee who worked not in a central office but from their homes, cars, and other new work sites. Further, Robbins and Coulter (1999) simplify telecommuting as a work design option in which workers are linked to the workplace by computers and modems.

Telecommuting refers to the capability of individuals to work at home and communicate with their offices using personal computers and communications equipment and software (Shelly et al. 1998). Williams et al. (1999) stated that computers and communications tools have led to telecommuting and telecommuting centers, the virtual office and "hoteling," and the mobile workplace. Further, Johnson (1999) discovered email and newsgroups is the primary form of communication.

Further, the mobile workforce is relatively new concept towards the Malaysian firms. Proponents said that telecommuting made the work force more efficient, cut costs and even help protect the environment (CNN 1996). Many companies were developing telecommuting programs as a way to draw new employees. With today's tight labor market, companies that offer 
Karia, Zainuddin, \& Abu Hassan Assari-Perception of Human Resources Managers on...

flexibility might have an edge over those who require all work to be done on site (Meyers 1998).

Williams et al. (1999) stated that the virtual office is an often nonpermanent and mobile office run using computer and communications technology. Knight and Westbrook (1999) supported and referred telecommuting as to employees who work predominantly outside of their home office, but were associated with a traditional office and may be used a traditional office for some administrative support and to hold physical meeting.

\section{Equipments}

Telecommuting had been promoted extensively in the United States somewhere in the 70s as personal computer, and portable modem had been made available (Roseberry 2001; USDT 1993; Hill et al. 1998). Telecommuting, as defined by Williams et al. (1999) is a way of working at home with telecommunications -phone, fax, and computer- between office and home. It is the ability to connect computers to one another by modem or network and communications lines to provide online information access, such as the use of pocket pagers, portable computers, fax machines, and various phone and network services to conduct business.

Telecommuters often used other communications media such as electronic mail, personal computer linked to office servers and fax machines (Kurland and Bailey 1999). Moreover, telecommuters need to have a main computer, a second computer, a phone, a network, and a printer to help them in their telecommuting (Finlay 1999). Schilling (1999) indicated that with telecommuting employees gave up costly office space and communicate with the company and their customers remotely by telephone, computer or other technologi- cal tools. Lovelace (1995) mentioned that people who regularly work from locations outside the office, telecommuting to the office by phone, fax and modem.

With the advancement of communications and information technology, the ability to log on the company's network easily from any location as well as the availability of devices like notebook computers, smart mobile phones and handheld devices has given rise to a trend of mobile computing and telecommuting (Anonymous 1999).

\section{Telecommuting Factors}

As the case of Malaysia, the exploration needs to be done in order to look for factors that may influence human resource managers of Malaysian firms to adopt telecommuting concept. Based on the Western studies, telecommuting does improve quality of work life. Additionally, it also improve productivity, morale, teamwork, flexibility, and work hours. Telecommuting has been foreseen way back as early as 1950s, it did not become practical until the advent of personal computers and portable modems in the early 1970s (USDT 1993; Hill et al. 1998). Further, as firms in Malaysia were not exposed to the telecommuting concept, factors will be developed based on the reviews and findings by Westerners.

Based on the literature reviews, many companies were developing telecommuting programs (CNN 1996). The studies showed that telecommuting could provide a substantial competitive advantage in workforce recruitment and retention, productivity, real estate and office overhead, customer service, and corporate image and goodwill (Anonymous 1998).

Knight and Westbrook (1999) stressed that greater emphasis were placed on hiring and retaining qualified workers, 
which often means dipping into a labor pool that requires greater flexibility, such as working parents and people with limited mobility. They also discovered that telecommuting helps to attract new employees, especially those who need flexibility, increases retention rates, reduces sick time and absenteeism, increases productivity and increases job satisfaction. In order to retain qualified workers, the organizations should allow people to telecommute from home, whether on a part-time or full-time basis. Telecommuting had become a valuable tactic in the fight to hire and retain skilled workers (Straton 2001; Fister 1999).

Fortier (1998) indicated that employees need flexibility and a balance between their work lives and their personal lives. Meanwhile, Kurland and Bailey (1999) mentioned another reason to implement telecommuting. That is, it widens the talent pool available to the organization. It also might stem turnover by providing workers with flexibility that allows them to keep their jobs in the face of external demands or desires. Telecommuting provided staffing flexibility where the staffs are able to work regardless of weather or traffic peaks (Langhoff 1996).

Home-based telecommuting provided an opportunity to improve workplace productivity (Kurland and Bailey 1999; Lovelace 1995). Because telecommuting employees experience greater schedule flexibility, they can work when they prefer, and thereby improve their productivity. Further, Kurland and Bailey (1999) stated popular press accounts of successful telecommuting programs often report that telecommuters take fewer sick days, are absent less, have higher job satisfaction, and have higher work performance ratings. These factors might positively affected productivity. Telecom- muters had relatively distraction-free environments, as they are more often to receive interruptions while at the traditional office (Kurland and Bailey 1999). Together, these factors, related to the location of work, the timing of work, and the quality of work life, can increase productivity. Subsequently, telecommuting improved productivity on the jobs (Fister 1999; Ervin 1998; Fortier 1998; Hill et al. 1998; White Paper 1997; Shellenbarger 1997; Sullivan 1992; and Janal 1991) and the improvement is ranged between 20 to 70 percent (Ervin 1998; Khairallah 2001; Straton 2001; and Verespej 2001). This also supported by Hawkins et al. (1997), CNN (1996), Langhoff (1996), and Pacholczyk et al. (1995) as they stated that telecommuting improved productivity and their organizations benefited from the practice.

Telecommuting saved company's money (Schilling 1999a). Employers initiated a telecommuting program save on leasing costs (Gage 1998). Further, Robertson (1998) indicated that mobile telecommuters are able to help the organization improve their level of customer service by reducing costs associated with office space and daily travel to the corporate office. Therefore, employees gave up costly office space and communicate with the company and their customers remotely by telephone, computer or other technological tools. Fortier (1998) indicated telecommuting can help to alleviate the office space crunch and is a great alternative to expensive new buildings. Further, Girard (1997) discovered that companies should save as they implement telecommuting. This is supported by Martin (1994) as he indicated that expense reduction for the corporation has been a major impetus for this large increase in the virtual office. Straton (2001) indicated that their com- 
Karia, Zainuddin, \& Abu Hassan Assari-Perception of Human Resources Managers on...

pany had decreased office space by 35 percent nationwide resulting in annual cost savings of over $\$ 3$ million dollars. Meanwhile, Milkovich (2001) stated that the cost savings in annual rent is 25 percent. AT\&T saved about \$25 million in realestate costs through telecommuting (Khairallah 2001).

Fortier (1998) stated that telecommuting could help organizations to reduce absenteeism among employees due to illness, childcare, eldercare, and the need to be home to take care of personal business. Further, he stated that telecommuting could mitigate business disruption during strikes, floods, bad weather, and other emergencies. In addition, CNN (1996) mentioned that those who could benefit most are women. By the turn of the century, an estimated four out of five women of childbearing age will be in the work force. Telecommuting and new technologies could help those women to better adjust their work schedules with motherhood.

Telecommuting could improve organizations' concern on the social responsibility towards the environment. As indicated by Lovelace (1995), telecommuting could avoid long commutes on congested highways or city streets, and to adjust their workday according to their needs, unbounded by traditional office hours. Meanwhile, society also benefits from telecommuting such as energy consumption, environmental degradation, reduce traffic congestion, and reduce pollution (Straton 2001; Milkovich 2001). Moreover, in London, telecommuting solved the chronic overcrowding by 25 percent reduction in the number of public transport users, cars, and people (Khairallah 2001).

\section{Methodology}

\section{Research Question}

The purpose of this study is to explore the factors that contribute telecommuting concept to be accepted by firms in Malaysia. Studies of factors by Westerners will be replicated and used in carrying out the research. Further, the study will identify which factors that contribute the most towards the implementation of telecommuting concept in the Malaysia firms. Finally, do Malaysian firms opt for telecommuting concept as a new work arrangement for Malaysian workers?

\section{Variables}

The dependent variables in the study were derived from various reviews that were discovered. After going through the factor analysis, twenty-four variables were grouped into five factors:

\section{Factor 1:}

1. Concern on employees who care for sick child/spouse.

2. Regularly work outstation.

3. Work transfer or relocation.

4. Improved staff retention.

5. Take care of family matters.

6. Take care of personal matters.

\section{Factor 2:}

1. Improved staff recruitment opportunities.

2. Job flexibility.

3. Long commutes to work.

4. Improve morale/motivation.

5. Distraction while at work.

6. Job satisfaction.

7. Environmental issues.

8. Working from home/mobile office.

9. Congested city streets. 
Factor 3:

1. Importance of co-workers' input to work function.

2. Absences from office as trouble free.

Factor 4:

1. Amount face-to-face contact required.

2. Manage by result.

3. Discipline regarding work.

Factor 5:

1. Amount of empowerment given to employees for completion of work.

2. Improved productivity.

3. Employee ability to control and schedule work flow.

4. Degree of concern on quality of work delivered.

The independent variables in this study will focus on the firm's environment that relates to gender of human resource managers and industry of the firm.

\section{Design of the Instrument}

A structured questionnaire was developed based on the evidence from the literatures. A Likert scale (from 1 to 6 ) was developed to identify the degree of agreement of the working environment factors.

\section{Sample}

The sample of this study was taken from the business directory and phone book of firms listed in the Northern Region of Malaysia. A questionnaire was mailed to the firms' human resource managers in getting the firms' view on the telecommuting concept.

\section{Questionnaire}

Questionnaires were distributed and administered toward human resource managers of Malaysian firms in the Northern states of Malaysia. The questionnaires were divided into two parts that sought demo- graphic information and factors of concern on telecommuting concept. Out of the 150 set of questionnaires distributed to human resource managers, 68 responded which give a response rate of 45.3 percent.

\section{Method of Analysis}

Data was analyzed using SPSS program. Initially, frequencies were run. Further, descriptive analysis was done in looking further for some descriptive of the population. Mean of the variables was generated in looking for some indicators from the population.

\section{Results}

\section{Overview of Data}

The sample profile information is depicted in Table 1. Majority of the respondents were male $(57.4 \%)$ as compared to female $(42.6 \%)$. Based on industry, the majority of the respondents were from services industry $(64.7 \%)$, followed by manufacturing (11.8\%), finance (2.9\%), and others $(4.5 \%)$. Further, based on the number of employees being employed, the majority $(72 \%)$ of the firms indicated that they employed less than 100 employees.

Human resource managers indicated their high-end concern (4 to 5-point Likert) as depicted in Table 2. As for discipline regarding work, 94.1 percent indicated their high concern on the factor. In terms of productivity improvement, human resource managers indicated 88.3 percent as their high concern. Quality of work delivered also being stressed as one of their main concern towards the establishment of the telecommuting concept of which 91.2 percent. Further, ability to communicate with employees, face-to-face contact required, and importance of co-workers' 
Karia, Zainuddin, \& Abu Hassan Assari-Perception of Human Resources Managers on...

Table 1. Sample Profile Information

\begin{tabular}{|c|c|c|c|}
\hline & Item & $\mathbf{N}$ & $\%$ \\
\hline \multirow[t]{3}{*}{ Gender } & Male & 39 & 57.4 \\
\hline & Female & 29 & 42.6 \\
\hline & TOTAL & 68 & 100.0 \\
\hline \multirow[t]{5}{*}{ Industry } & Services & 44 & 64.7 \\
\hline & Finance & 2 & 2.9 \\
\hline & Manufacturing & 8 & 11.8 \\
\hline & Others & 3 & 4.5 \\
\hline & TOTAL & 57 & 83.9 \\
\hline \multirow[t]{7}{*}{ Number of Employees } & Less than 1000 & 46 & 71.9 \\
\hline & 1001 to 2000 & 5 & 7.8 \\
\hline & 2001 to 3000 & 7 & 10.9 \\
\hline & 3001 to 4000 & 1 & 1.6 \\
\hline & 4001 to 5000 & 4 & 6.3 \\
\hline & More than 5001 & 1 & 1.6 \\
\hline & TOTAL & 64 & 100.1 \\
\hline
\end{tabular}

Table 2. High-end Concern of Human Resource Managers

\begin{tabular}{|c|c|c|}
\hline Degree of concern & $\mathbf{N}$ & $\%$ \\
\hline Discipline regarding work & 64 & 94.1 \\
\hline Improved productivity & 60 & 88.3 \\
\hline Quality of work & 60 & 91.2 \\
\hline Ability to communicate with employees & 57 & 83.8 \\
\hline Face-to-face contact required & 57 & 83.9 \\
\hline Importance of co-workers' input to work function & 56 & 82.3 \\
\hline
\end{tabular}

input to work function were indicated as 83.8 percent, 83.9 percent, and 82.3 percent respectively.

\section{Data Analysis}

Further analysis of the variables is based on mean comparison against type of organizations -public and private. It was discovered that both types of organizations indicated the degree of concern on quality of work delivered as marked towards the highest end (mean: 4.6471 for public and 5.0000 for private). Moreover, amount of face-to-face contact required, importance of co-workers' input to work functions, discipline regarding work, management by result, required concentration and peace to do the work, improved productivity, and job satisfaction were also marked as the highest by the respondent (see Table 3).

A factor analysis was conducted over 22 variables in this study. The variables were grouped into 5 factors. The overall 
Gadjah Mada International Journal of Business, January 2003, Vol. 5, No. 1

Table 3. Comparison of Mean Between Types of Organization

\begin{tabular}{lllll}
\hline \multicolumn{1}{c}{ Variables } & & Public & & Private \\
\cline { 1 - 1 } Degree of concern on quality of work delivered & & 4.6471 & & 5.0000 \\
Amount of face-to-face contact required & & 4.5098 & & 4.9286 \\
Importance of co-workers' input to work function & & 4.3333 & & 4.9286 \\
Discipline regarding work & & 4.9216 & & 4.9286 \\
Management by result & & 4.5686 & & 4.2143 \\
Require concentration and peace to do the work & & 4.6364 & & 5.3333 \\
Improved productivity & & 4.7647 & & 4.6429 \\
Job satisfaction & & 4.4510 & & 4.5000 \\
\hline
\end{tabular}

Table 4. Factor Analysis

\begin{tabular}{|c|c|c|c|c|}
\hline Item & Mean & SD & Min & $\operatorname{Max}$ \\
\hline Factor 4 & 4.6667 & 0.6983 & 2.00 & 6.00 \\
\hline Factor 5 & 4.4029 & 0.7184 & 2.25 & 6.00 \\
\hline Factor 3 & 3.9412 & 0.9254 & 2.00 & 6.00 \\
\hline Factor 1 & 3.8436 & 0.8828 & 1.33 & 5.33 \\
\hline Factor 2 & 3.7967 & 0.8581 & 1.11 & 5.44 \\
\hline
\end{tabular}

Table 5. Mean for Significance Analysis - Gender

\begin{tabular}{|c|c|c|c|c|}
\hline \multirow[b]{2}{*}{ Factor 5} & \multirow{3}{*}{$\begin{array}{l}\text { Male } \\
\text { Female }\end{array}$} & \multirow{2}{*}{$\begin{array}{l}\text { Mean } \\
4.6474\end{array}$} & \multirow{2}{*}{$\frac{\text { SD }}{0.4978}$} & \multirow{3}{*}{$\begin{array}{l}\text { Sig. } \\
0.002\end{array}$} \\
\hline & & & & \\
\hline & & 4.0741 & 0.8388 & \\
\hline \multirow[t]{2}{*}{ Factor 1} & Male & 4.0137 & 0.7389 & 0.035 \\
\hline & Female & 3.6149 & 1.0145 & \\
\hline
\end{tabular}

mean score by the human resource managers on each factors of telecommuting concept are illustrated in Table 4. In summary, the degree of agreement on 5 factors of telecommuting was largely positive. The standard deviations were quite high, indicating that the dispersion was widely spread a distribution. It means that the factors of the telecommuting were approximation to a normal distribution.

Further, significance analysis was conducted on five factors on the telework acceptance from the perspective of gender. The result indicated only two factors, Factor 5 and 1, show the significance level. The analysis was depicted in Table 5. 
Karia, Zainuddin, \& Abu Hassan Assari-Perception of Human Resources Managers on...

\section{Discussions and Implications}

The factors of discipline regarding work, improved productivity, and degree of concern on quality of work delivered had been the motivating factors for the human resource managers to consider telecommuting as part of their organization in paving new lights to the way they do work. For factor of discipline regarding work, the human resource managers indicated as the highest importance to them that represented by 70.6 percent. In relation to productivity, 66.2 percent indicated their highest importance on improved productivity factor. Further, human resources manager indicated that 63.3 percent claimed highest importance on the degree of concern on quality of work delivered. From these results, it can be concluded that most human resource managers are eager to and looking forward with the implementation of telecommuting concept in their organizations, as they are concern on the output produced by the employees.

Moreover, the human resource managers indicated that management by result and improved morale or motivation did influence them in looking forward for telecommuting concept. This can be seen as they claimed 51.5 percent highest concern on their management by result. Factor of improved morale or motivation were 61.2 percent as claimed by the managers.

Meanwhile, the factors of ability to communicate with employees and amount of face-to-face were considered with high mean, 53 percent, as the human resource managers do need to interact with their employees from time to time in ensuring the work done.

Comparison based on mean between public and private organizations shown the concern of human resource managers in the implementation of telecommuting concept. Thus the organizations need to consider the following factors to be incorporated as motivators toward the implementation of the telecommuting concept:

1. Degree of concern on quality of work delivered.

2. Amount of face-to-face contact required.

3. Importance of co-workers' input to work function.

4. Discipline regarding work.

5. Management by result.

6. Require concentration and peace to do the work.

7. Improved productivity.

8. Job satisfaction.

Factor analysis shown that Factor 4 is regarded as the most concern of the human resource managers in determining the implementation of the telecommuting concept. These human resource managers are looking at the delivery of productivity by the individual workers. Meanwhile, Factor 5 that stressed on the quality and productivity from the perspective of the human resource managers also being one of the determining factors of telecommuting concept implementation.

Based on the independent samples ttest being conducted on the gender, it was discovered that male and female human resource managers had a significant difference on Factor 5, significance of 0.002 $(p<0.05)$. Thus, male human resource managers were more open towards the acceptance of telecommuting concept as compare to female. Further, they also shown a significant difference on Factor 1, significance of $0.035(\mathrm{p}<0.10)$. This shown that male human resource managers again are more supportive toward the implementation of telecommuting concept in their organization as compared to female human resource managers. 
Based on the types of organizations, there was no significant difference between public and private organizations towards the implementation of telecommuting concept. Moreover, based on the type of industry, human resource managers also shown no significant difference of their perception on the implementation of the telecommuting concept.

\section{Conclussion}

Generally, telecommuting concept is new to Malaysian firms, especially for the human resource managers. Some how, the concept needs to be introduced gradually to the firms in Malaysia. This introduction is needed as the nation is growing to become an industrialized nation by the year 2020 in materializing the vision of the Prime Minister Dr. Mahathir Mohamad.
Moreover, a paradigm change of the human resource managers of Malaysian firms need to be implemented as telecommuting concept is one of the new ways of getting the work done. Further, the support from the Ministry of Human Resources will give an added advantage towards the acceptance of the telecommuting concept. As Malaysia enters the information and telecommunications technologies, the result of the study can be used to gauge the Malaysian firms in preparing themselves towards the new era of working environment.

Finally, a quote from Milkovich (2001) indicated that developing and implementing a successful telecommuting program is actually simple and a matter of methodology. It requires strong organizational leadership on the front end coupled with support from the management level.

\section{References}

Anonymous. 1998. The 3 Whys of Telecommuting (April 7). TSI Services, Inc.

Anonymous. 1999. Demand for mobile devices on the rise. Computimes Malaysia (September 30).

Cable News Network (CNN). 1996. Despite Its Advantages, Telecommuting Slow to Catch On (September 11).

Finley, M. 1999. Making a telecommuting wish list. Computer User 8 (8) (August). Minneapolis.

Hill, J. E., B. C. Miller, and S. P. Weiner. 1998. Influences of the virtual office on aspects of work and work/life balance. Personnel Psychology 51 (3) (Autumn). Durham.

Johnson, D. 1999. Flexible hours, flexible rules. Home Office Computing 17 (7) (July). Boulder.

Khairallah, K. 2001. Get a life, leave London. New Statesman 130 (4526) (February 26).

Knight, P. J., and J. Westbrook. 1999. Comparing employees in traditional job structures vs. telecommuting jobs using Herzberg's hygiene and motivators. Engineering Management Journal 11 (1) March. 
Karia, Zainuddin, \& Abu Hassan Assari-Perception of Human Resources Managers on...

Kurland, N. B., and E. D. Bailey. 1999. Telecommuting: The advantages and challenges of working here, there, anywhere, and anytime. Organizational Dynamics 28 (2) (Autumn). New York.

Lovelace, G. 1995. Creating the framework for a mobile workforce. Telesis (100) (October). Ottawa.

Meyers, J. 1998. Free-from office work. Sacramento Business Journal (November 16).

Roseberry, C. 2001. Make sure you have the tools to succeed. http:// telecommuting.about.com 4 (34) (August 31).

Robbins, S.P., and M. Coulter. 1999. Management (6 Ed. International Edition). New Jersey: Prentice-Hall, Inc.

Shelly, G. B., T. J. Cashman, G. A. Waggoner, and W. C. Waggoner. 1998. Discovering computers 98: A link to the future. Course Technology. Massachusetts, USA.

Schilling, S. L. 1999. The basic of successful telecommuting network. HR Focus 76 (6) (June). New York.

Straton, M.C. 2001. Public and private approaches to telecommuting. FDCH Congressional Testimony (9/6).

U.S. Department of Transportation (USDT). 1993. Transportation Implications of Telecommuting. Washington DC: Author.

Verespej, M.A. 2001. The compelling case for telecommuting. Industry Week (September).

Williams, B. K., S. C. Sawyer, and S. E. Hutchinson. 1999. Using Information Technology: A Practical Introduction to Computers \&Telecommunications ( $3^{\text {rd }}$ Ed.). United States of America: Irwin McGraw-Hill. 